Article

\title{
Memes of Gandhi and Mercury in Anti-Vaccination Discourse
}

\author{
Jan Buts \\ School of Languages, Literatures and Cultural Studies, Trinity College Dublin, Dublin 2, Ireland; E-Mail: butsj@tcd.ie
}

Submitted: 30 January 2020 | Accepted: 11 May 2020 | Published: 26 June 2020

\begin{abstract}
This study focuses on two widely circulating memes in the anti-vaccination movement, namely lists of vaccine ingredients containing mercury, and quotes attributed to Mahatma Gandhi. Mercury has been identified by conspiracy theorists as one of the most harmful components of vaccines, and Gandhi, who has condemned vaccination practices, has been celebrated as a significant source of authority. Quotes attributed to Gandhi against vaccination, complete with picture and embellished font, circulate across various popular platforms, as do intimidating images of syringes dipped in poison coupled with a list of seemingly occult or dangerous ingredients. This article analyses both memes, moving from the imageboard 4chan to the search engine Google Images, and illustrates how the repurposed, often ironic use of visual tropes can either undermine or strengthen the claims that accompany them. The aim is to explore the intersections of conspiracy theory, visual rhetoric, and digital communication in order to elucidate the ambiguity of memes as vehicles for the spread of controversial health-related information.
\end{abstract}

\section{Keywords}

conspiracy theories; memes; misinformation; vaccination

\section{Issue}

This article is part of the issue "Health and Science Controversies in the Digital World: News, Mis/Disinformation and Public Engagement" edited by An Nguyen (Bournemouth University, UK) and Daniel Catalan (University Carlos III of Madrid, Spain).

(C) 2020 by the author; licensee Cogitatio (Lisbon, Portugal). This article is licensed under a Creative Commons Attribution 4.0 International License (CC BY).

\section{Introduction}

The development of the Internet has significantly facilitated the production, exchange, and consumption of information (Chadwick, 2006, p. 53). In this regard, dreams of global democracy and informed citizenship have been offset by increased fears of extensive manipulation and propaganda, as well as by the sheer overload of available information (Curran, 2012, p. 3). The kaleidoscopic clash of viewpoints generated through this medium has not inaugurated a novel period of enlightenment, but rather eroded trust in mechanisms of representation and the authority of expert discourse. In this climate, conspiracy theories perpetuating "stigmatized knowledge" not accepted by "mainstream institutions" have surfaced as a major force of social contestation (Barkun, 2013, p. 12). Conspiracy theories, or narratives of secret and evil-minded social machinations, are not a new phenomenon. They have for centuries sustained the vilifi- cation of secret societies and of Jews (Aupers, 2012, pp. 24-26). The period immediately before the Internet era saw well-documented examples such as the stories surrounding the murder of John F. Kennedy and the alleged extraterrestrial presence at Area 51. Yet currently conspiracy theories are rapidly multiplying and are often supported by a worldwide activist base. Consequently, political and media authorities have taken extensive measures to silence dissenting voices. Infowars' Alex Jones for instance, a known contributor to a variety of stigmatized narratives, was banned from Facebook, Spotify, Apple and YouTube for supposedly promoting violence and hate speech (Hern, 2018). On the other hand, Jones was reported to be an influential figure in the Trump campaign (Corn, 2017). In the medical sphere, the World Health Organization has recently declared 'vaccine hesitancy' as one of its major health concerns, in response to the growing rise of the anti-vaccination movement, a loose-knit community of people who believe that vacci- 
nation is dangerous and conducted for sinister purposes (World Health Organization, 2019). In short, conspiracy theories are a major force in today's political and scientific debates.

Conspiracy theories have been extensively studied from philosophical, psychological, and sociological perspectives (e.g., Douglas, Sutton, \& Cichocka, 2017; Harambam \& Aupers, 2015; Keeley, 1999). Descriptive and explanatory efforts in this regard often proceed from the assumption that if the genesis and patterns of spread of conspiratorial thought can be understood, instances of misinformation can be effectively combatted. Kata (2011, p. 3785), for example, provides an in-depth analysis of discursive strategies used by online proponents of alternative health rhetoric, arguing that "truly informed choices" can only proceed from the recognition of "tactics and tropes" employed by the anti-vaccination movement. However, recognition is often a reciprocal process, and proponents of misinformation have no trouble mimicking the tactics and tropes of general medical or governmental discourse. In January 2020, for instance, the Australian Involuntary Medication Objectors Party, which campaigns against compulsory vaccination, announced its plans to be known, from then on, as the Informed Medical Options Party (Mourad, 2020). Keeping the same acronym, the organisation thus coopts the rhetoric of informed choice. This example suggests that cultural antagonism may result in the imitation or replication of discursive characteristics. The present article argues that one of the main challenges for identifying and consequently combatting misinformation in the medical sphere is the fact that there are often no distinguishing features between the visual and textual means used by proponents and opponents of, in this case, vaccination.

The argument is supported through the analysis of examples drawn from 4chan's discussion forum /pol/, a popular anonymous imageboard and a hotbed of meme culture. Previous studies have researched the influence of 4chan on other online platforms from a large-scale quantitative perspective (Hine et al., 2017; Zannettou et al., 2017). The present article initially presents a platform-internal, qualitative study of two memes found in a single thread on $/ \mathrm{pol} /$. The thread was selected from the 4 plebs archive. The original poster explicitly mentions his distrust of information provided by the media and the government regarding a possible link between autism and vaccines, and thus refers to a central node of contention in the broader vaccination debate. Furthermore, the thread was markedly more popular than the average thread on /pol/ and contains a relatively high number of images. In addition, the images in the thread can be divided into distinct categories, such as graphs, frogs, quotations and lists of ingredients. I focus on the latter two categories. The analysis is partly textual and partly visual, as the quotation format in the thread typically includes the outline of a famous face and lists of ingredients are often coupled with the image of a sy- ringe. Both formats constitute image macros, a category of Internet memes composed of variable text superimposed upon a recurrent image.

The analysis proceeds from the observation that a meme, rather than being a solid and static entity, primarily consists of an iterable "contour organized around certain visual characteristics" (Pelletier-Gagnon \& Diniz, 2018 , p. 9). In other words, a meme is defined by its shape or outline, and not by its informational content. I illustrate the dispersion of the memetic outlines or contours encountered on 4chan by using Google Images. This procedure illustrates how, outside of 4chan, the same image of a syringe occurs across various social media platforms, although each time for different communicative purposes. In the case of quotations, it is shown how the authority of Gandhi, a popular source of inspiration on the Internet, has in recent years been subverted by online actors using his image for humorous purposes. I demonstrate that while meme culture may initially facilitate the rapid spread of disinformation, the fast-paced ironic replication of semiotic elements ultimately voids the argumentative consistency of the memetic artefacts involved. The article thus puts forward the hypothesis that, within the discursive universe of the online anti-vaccination movement, the disease and the cure seemingly constitute two sides of the same coin: the propagation and demise of memetic templates and the content they accompany constitute one process. As a meme adapts to serve a variety of communicative purposes and in the process undergoes a series of ironic reversals, it becomes more visible but less suitable for (mis-)informational purposes.

\section{Memes and /pol/}

Recognizable and iterable symbols govern social interaction on the Internet, as is evident from the rising significance of Internet memes. Internet memes are units of cultural replication that are often humorous and highly derivative. Most memes take the form of a simple combination of image and text. Before the term 'meme' became popularized in this sense, its scholarly definition included "tunes, ideas, catch-phrases, clothes fashions" and even "ways of making pots or of building arches" (Dawkins, 2003, p. 192). The rather specific meaning attached to the term today reveals how ironic templates circulating on fora such as Reddit and 4chan have left the periphery to occupy a position of central cultural importance. In this regard, the rapid spread and demise of memetic formats is symptomatic of an ever more "accelerative culture" steeped in a process of ongoing "bricolage" (Urban, 2001, pp. 18, 127). Often short but intense, a successful meme's life tends to be full of reversals of fate.

The highly visible meme Pepe the Frog, for instance, was created in 2005 by Matt Furie as an animal expression of contentment. Online, the frog was welcomed by various artistic communities, yet a decade after its cre- 
ation it came to be perceived as an 'alt-right' symbol. After an unsuccessful reclamation campaign on social media, the frog, by then on the Anti-Defamation League's list of hate symbols, was vainly declared dead by its creator (Hunt, 2017). In 2019, Pepe, seemingly out of nothing, reappeared in the streets of Hong Kong as a symbol of anti-authoritarianism (Ellis, 2019). Each reiteration of the meme seems to arise in disregard of the intentions of its previous users. Today, Internet memes simultaneously "constitute the cultural backbone of online communities" and thrive most when they can be continuously "altered and repurposed" (Pelletier-Gagnon \& Diniz, 2018, pp. 3-4). Indeed, it could be argued that the value of a meme is equal to its capacity to have its meaning radically transformed, and in this sense irony, both as a humorous strategy and as reversal of intent, governs much of today's cultural production.

The trajectory of Pepe the Frog was heavily influenced by its use on the imageboard 4chan, where the association with Trump supporters, and eventually the 'alt-right,' took hold. The subversion of innocent or ideologically loaded imagery is a common source of amusement on 4chan. For instance, the forum regularly hosts calls for repurposing the rainbow flag as a symbol of ethnonationalism, accompanied by slogans such as "defend diversity-a separate place for every race" (Anonymous, 2020a). Once such memes circulate beyond the confines of 4 chan, they contaminate the broader realms of social and traditional media, and the original symbolic connection, in this case between the rainbow flag and the LGBTQ+ community, becomes tainted. The goal of parasitic cultural artefacts like the repurposed rainbow flag is not quite the actual establishment of ethnic nation states, but rather working contrary to the progressive calls for diversity that govern much of today's political discourse. Such efforts exemplify the practice of 'trolling'generating the maximum amount of polemic and agitation with the least amount of investment. Trolls often seek to create the impression "that nothing should be taken seriously" (Phillips, 2012, p. 499). In this respect, they find fertile ground in the discourse of conspiracy theory. The rise of the Flat Earth theory, for instance, evokes in a large part of the populace a deep sense of doubt, not about the shape of the earth but about their interlocutor's true intentions: Are you being serious? In short, a cultural milieu of irony may come to erode the foundations of interpersonal trust and epistemological reasoning. In that respect, memes do not have to be taken seriously by their users to have serious consequences.

The adaptations, iterations and reversals of the memescape take place in a cross-platform environment, and the origin and spread of memes is being meticulously documented on websites such as knowyourmeme.com. Increasingly, scholars are turning to the question of measuring the impact of certain fora on the production and dissemination of memes or related Internet content. 4chan, while understudied if compared to platforms such as Twitter or YouTube, is assuming an increas- ingly important place in this burgeoning field of study. On 4chan, people post threads on a board that suits their interests. The first post consists of an image and text. Those responding to the original post can choose whether to include an image. Boards are focused on topics such as 'literature' or 'fitness,' but may be more open, as in the case of the 'random' board. Phillips (2012, p. 496) characterised the 'random' board, or /b/, as "arguably the epicenter of online trolling activity." On 4chan, users typically post anonymously, and their posts are ephemeral, as threads are regularly removed from the boards. A great number of threads receive no replies at all before disappearing from the board (Bernstein et al., 2011 , p. 54). These characteristics make 4chan relatively difficult to study in any sort of comprehensive way, yet studies such as Hine et al. (2017) and Zannettou et al. (2017) indicate the usefulness of a quantitative methodology for analysing 4chan as part of the broader hyperlinked media ecosystem. Both these studies are focused on /pol/, or the 'politically incorrect' board, a board "for the discussion of news, world events, political issues, and other related topics" (Anonymous, 2017). /Pol/ has been described as "subscribing to the alt-right and exhibiting characteristics of xenophobia, social conservatism and, generally speaking, hate" (Hine et al., 2017, p. 92).

Although 4chan's lack of a direct archival function has been addressed as a distinctive characteristic of the platform (Nissenbaum \& Shifman, 2017), consistent documentation efforts have been ongoing at least since 2013 . A number of boards, among them /pol/, are archived on the 4 plebs website, accompanied by useful statistics (4plebs, 2020). The website reveals, for instance, that the two most popular archived threads on /pol/ concern the 2016 presidential election and the 2016 EU referendum, with more than 73,000 and 58,000 posts respectively. Among the images that have been reposted the most are innumerable frogs, several versions of Donald Trump, and many variations on the stereotype of the evil hand-wringing Jew, reminiscent of Dickens's Fagin or Shakespeare's Shylock. On /pol/, Jews are held responsible, with what appear to be varying degrees of genuine conviction, for a host of calamities. A recurrent 'Jewish trick' discussed on the board is effecting the degeneration of the white race and its culture through enforced migration and multiculturalism, while the Jews supposedly keep their own bloodline 'pure'. The growing influence of LGBTQ+ culture is also presented as part of a Jewish conspiracy to undermine the strength of Western civilization. Jews are further said not to vaccinate themselves, while globally promoting compulsory vaccination programs. This study deals with the vaccination debate and does not further address the hatred and suspicion towards Jews on 4chan. Jokingly or otherwise, the expression of this hatred is highly diffuse and evident in almost every discussion on the board. Vaccination, on the other hand, is a specific topic with a persistent presence on /pol/ as a concern in itself, rather than as an addendum to any other issue. The 4 plebs archive features several 
threads concerned with vaccination for each month of every year for the last half decade. Some of these threads do not receive any responses, yet some generate considerable debate.

In what follows, I will focus on one recent, quite successful thread (200 replies) in which several central characteristics of online vaccination hesitancy converge. All quotes from this thread will be referenced as 'Anonymous, 2019', and a link to the archived thread is provided in the reference list. The original post, dated 23 May 2019 and accompanied by what seems to be an unrelated image of a female athlete, reads as follows:

Just had a long fight with my fiance and her mom about vaccines. I just dont trust the government and media to be telling me the truth, and when theyre in lockstep telling me to do something and offering it for free I just assume malicious intent....Can I get some redpills on vaccines? am i being a retard or are they legitimately going to give our kids autism? (Anonymous, 2019)

The post reveals a broad distrust of the government and the media, and articulates the supposed link between vaccines and autism, a major point of contention in the information wars about vaccine safety. In the thread that follows in response to the post, opinions on vaccination are varied and sometimes opposed. Across the spectrum, a considerable amount of external information is referenced. Posts direct others towards sources that support their authors' stances, from folk documentaries to alleged specialist literature. Titles such as 'Dr.' are explicitly used on a board otherwise unconcerned with verbal etiquette. A recurrent figure is Dr. Wakefield, whose study on MMR vaccination and autism, although condemned by the scientific community and long retracted by The Lancet, remains hugely influential in antivaccination discourse (Wakefield et al., 1998). While the authority of the scientific community as a whole is thus rejected by those contesting vaccination, the authority of a single 'Dr.' is asserted with great conviction. At work here is a peculiar phenomenon where expertise as a general value is discarded, except when it supports a single seemingly predetermined viewpoint.

A "profound distrust in elites and experts" is intimately associated with populist politics, and it has been suggested that vaccine hesitancy and support for populist politicians in Western Europe tend to co-occur (Kennedy, 2019, p. 515). In the United States, too, antiintellectual attitudes have had political consequences. The Trump campaign, for instance, is very suspicious of 'climate scientists,' and Trump has questioned the safety of vaccines before (Motta, 2018, p. 466). Thus, opinions on vaccination are often heavily politicised and culturally dependent, and they may change rapidly as alliances shift. As research on the long and global history of the phenomenon illustrates, resistance to vaccination has existed since Edward Jenner, now more than 200 years ago, used the method to induce immunity against smallpox in a patient (Holberg, Blume, \& Greenough, 2017). Resistance has come in many forms, from official societies to personal abstentions, and the 'anti-vaccination movement' is not a uniform body, but rather a label that includes anyone sceptical about vaccination practices. However, throughout the history of the 'movement,' one finds a number of recurring characteristics uniting expressions of suspicion by otherwise unaffiliated individuals. Two such characteristics, namely distrust of chemical elements and selective reliance upon figures of authority, are discussed in the two following sections with reference 4chan's /pol/. The analysis illustrates that Internet memes may contribute to the promotion of anti-vaccination discourse but may also undermine the credibility of its message.

\section{Quoting Gandhi}

One of the functions of quotation is to invoke authority. A quote may contribute to what Atkins and Finlayson (2016, p. 164), drawing on the Western rhetorical tradition's modes of persuasion, term the 'logos', the 'pathos' and the 'ethos' of an argument. Logos is the locus where "evidence for claims" is provided, while pathos relates to sentiment, humour, and the use of "elevated language" (Atkins \& Finlayson, 2016, p. 164). Ethos, finally, establishes a speaker's character, "including their identification with a particular community or cultural milieu" (Atkins \& Finlayson, 2016, p. 164). In a hyperlinked environment, there are various means available to fulfil such functions, but quotation is remarkably common on 4chan. Quite often, quotes appear in the form of an image of the speaker's face, accompanied by a stretch of text and the attribution. People quoted in this manner in the thread under consideration are Robert F. Kennedy Jr., William W. Thompson, Mahatma Gandhi, Dr. Ron Paul, Mark Twain, Bill Gates, Søren Kierkegaard, Nikola Tesla, George Orwell, and Georg Wilhelm Friedrich Hegel. A general ethos or cultural milieu cannot immediately be derived from such a varied list, and it is remarkable that not many of those listed are referenced specifically for their views on vaccination. Indeed, some, such as Hegel, predate the invention of the practice. In one response to the initial post, Mark Twain is (potentially incorrectly) attributed the quote "It's easier to fool people than to convince them they have been fooled" (Anonymous, 2019). Kierkegaard too, is referenced in the broad context of being fooled, and Orwell is invoked regarding "times of universal deceit" (Anonymous, 2019). Tesla is simply referenced regarding the possibility of an endless supply of energy. The quote is not further contextualized but its inclusion suggests that vaccines are just one of the domains in which the powerful are holding back information that might deliver the general populace from toil and evil.

The case of Bill Gates is more complicated, as the quote refers to a TED Talk on climate change in which he suggested that vaccines may help bring down the 
population. Gates's remarks are initially surprising yet unremarkable in the context of his talk-general improvements in healthcare can be associated with limited population growth. However, they are interpreted on the board as if he let slip the murderous motivations of humanity's governing order. At the time of writing, similar suspicions are arising around Event 201, a 2019 event hosted by the Gates Foundation involving the simulation of a coronavirus pandemic and thus eerily prefigurative of the COVID-19 outbreak (Fichera, 2020). Of the remainder of people who are quoted on vaccination proper, Kennedy, nephew of the former president, appears first, with the argument that vaccination is a burden on the taxpayer. William W. Thompson is presented as a scientist turned whistle-blower who uncovered a hidden study that once again linked vaccines and autism. Dr. Ron Paul is presented as condemning the totalitarian characteristics of "mandatory and forced vaccination" (Anonymous, 2019). The image of Mahatma Gandhi, finally, is accompanied by the following quote: "Vaccination is a barbarous practice and one of the most fatal of all the delusions current in our time. Conscientious objectors to vaccination should stand alone, if need be, against the whole world, in defence of their conviction" (Anonymous, 2019).

Gandhi often appears on 4chan, across several boards, as well as on a host of other platforms, accompanied by faux quotes such as "bitches ain't shit but hoes and tricks" (e.g. u/dchubbs, 2013), lyrics that should properly be attributed to the musician Dr Dre. Attributing false quotes to Gandhi, as well as, for instance, to Albert Einstein and Abraham Lincoln, is a popular practice on the Internet, partly deriving its iconoclastic, humorous quality from the fact that sharing actual Gandhi quotations online is also a widespread phenomenon: the popular website BrainyQuote (2020) features Gandhi on its short 'authors to explore' list, and AZ Quotes (2020) features him among its 'popular authors.' His image is part of the latter website's background. On Goodreads (2020), his "be the change you want to see in the world" is one of the 10 most popular quotes, boasting more than 100,000 likes. In most online instances, Gandhi quotes are accompanied by his familiar bespectacled image (Figure 1).

When uploaded into the Google Images search box, the Gandhi image from the 4chan thread returns dozens of similar images and associated quotes (with limited influence from search history across browsers and ma- chines). About one fourth of the quotes tends to be false, with examples ranging from the parodical "you must be the meme you want to see in the world" (Me.me, n.d.) to the more absurd "it's just a prank bro" (Know Your Meme, 2016). While Google Images search is never neutral and by no means a tool that easily allows for experimental control, it is an accurate pathway for mimicking people's day-to-day encounter with online material, as Google remains the most visited website in the world. Furthermore, Google Images search tends to return images with a similar composition, and is therefore highly effective in tracing memes, which are primarily determined by their contour, or the shape that contains the message. Following Dennett (2017), Pelletier-Gagnon and Diniz (2018, p. 2) argue that memes are primarily a "design worth copying," and that they do "not necessarily transmit reliable information." The specific usage of Gandhi as a vessel for carrying inaccurate quotes confirms this perspective. The sheer quantity of quotes falsely attributed to Gandhi, often in a trolling context, make it likely for 4chan users to be primed not to take Gandhi quotations seriously. In other words, while his appearance contributes to the comic pathos and ironic ethos that define the imageboard's community, Gandhi is by default not expected to contribute to the logos of an argument by introducing support or proof for one's stance.

Nevertheless, the Gandhi quote on vaccination cited above is correctly attributed, and can be found in Gandhi's A Guide to Health (1921, pp. 105-112). Gandhi, "a vocal opponent to western medicine," believed that vaccination "hindered discipline over the body and control over the mind" (Brimnes, 2017, pp. 57-58). In rejecting vaccination, Gandhi used his power as a member of the cultural elite to question scientific expertise, and thus combatted authority with authority. The argument he presents in the book features logical fallacies and favours anecdotal accounts over scientific evidence, but the primary mechanism Gandhi mobilizes is that of emotion, and more specifically, disgust. He manages to cast aside the opinion of specialists in the field by zooming in on the abject qualities of microscopic medicine. In his book, a vaccine is said to be "a filthy substance" and vaccination is described as "injecting into the skin the liquid that is obtained by applying the discharge from the body of a small-pox patient to the udder of a cow" (Gandhi, 1921, p. 105). The latter sentence does not
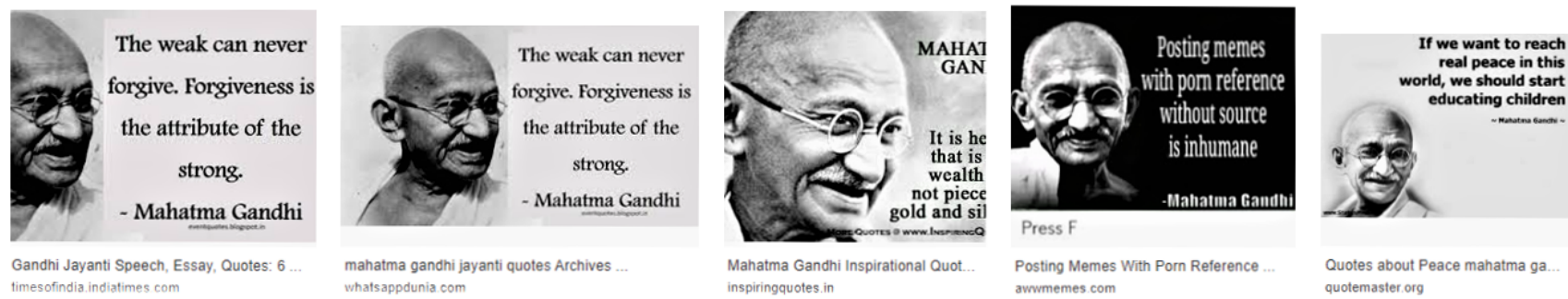

Figure 1. Various instances of typical Gandhi quotation format. Source: Google Images (2019). 
read easily in translation, but there is no need for it to be fully transparent. The result, a list of disgusting procedures and objects, should be enough to conjure up the image of a poisonous, or at least repulsive concoction. Furthermore, Gandhi profits from the fact that vaccination is a fundamentally counter-intuitive operation. Breaching the integrity of the body is usually associated with harm rather than healing. In rejecting vaccination, one's instincts about protection thus lead to its lack. For Gandhi and those who agree with him on the subject, it is of relatively little importance whether vaccines are necessary, but of great importance that they are frightening and disgusting, and thus evoke a response of refusal. On 4chan, however, Gandhi has no power to wield, as his online identity has already fallen victim to extensive memetic repurposing. His image is not associated with truth and seriousness, and an encounter with his face is likely to bring mere anticipation of the absurd. His argumentative strategies, however, which include the listing of ingredients for instigating fear and disgust, are more abiding, as the next section illustrates.

\section{Mentioning Mercury}

Apart from the talking heads discussed in the previous section, two outlines or contours stand out among the four dozen images that occur within the /pol/ thread under scrutiny. The first contour is that of the graph. Typically, the graph serves to indicate the rising incidence of a plethora of pathological conditions, associated with either the rising number of specific vaccines, or the rising number of people who are vaccinated. The second contour is that of the syringe. Given the previous discussion of intuitive resistance to needles entering one's body, the needle is a far from innocent representative artefact. Indeed, the Diagnostic and Statistical Manual of Mental Disorders, in its discussion of phobias, prominently features a separate coding for the fear of "needles" and "invasive medical procedures" (American Psychiatric Association, 2013, p. 198).

In the thread under discussion, the image of a needle typically co-occurs with a list of vaccine ingredients. Mercury and aluminium feature most frequently. One of the images explains that a single flu vaccine contains more mercury parts per billion than does hazardous waste, with the image of the needle printed twice as large as that of a barrel with a radioactivity warning sign. Another image features an apple surrounded by needles that carry the following inscriptions: "Mercury (a known neurotoxin), Aluminium (a known neurotoxin), Polysorbate 80 (a known carcinogen), aborted fetal cells, GMO Bacteria \& DNA, Formaldehyde" (Anonymous, 2019). The suggestion is that nobody would eat an apple injected with those substances. The question, then, is why we allow them in our bloodstream. Interestingly, the first three elements listed carry some sort of medical explanation of harm, involving cancer or the neural system. The other three elements seem not to require such an explanation; the absence of an explanation, one could argue, can be ascribed to the fact that the elements are considered disgusting in and of themselves. Formaldehyde carries a revolting smell, bacteria are the enemy of sanitized society, and the suggested consumption of "aborted fetal cells" goes, for some, against all that is good and holy. From this perspective, it is far from surprising that Gandhi would associate Western medicine and its vaccination practice with black magic (Brimnes, 2017, p. 58). Variations on this theme are present in the /pol/ thread not only in the images posted, but also in the text:

Read the ingredients here on the CDC [Centers for Disease Control and Prevention] site and see that aborted human fetal tissue, aluminium (lots of it), bovine serum, chicken serum, eagle serum, monkey liver, polysorbate 80 , formaldehyde and many other carcinogens and preservatives are injected straight into the blood stream. (Anonymous, 2019)

The Centers for Disease Control and Prevention is a leading public health body, and by no means a fringe society for alternative medicine. The link the anonymous poster provides genuinely directs there, and all the ingredients mentioned, in some form or another, do form part of particular vaccines. It is, however, the cumulative effect imparted by the poster that transforms these individual ingredients from technical accessories into components of a witch's brew. As observed by Eco (2009, p. 133), the figure of the list is often one of "accumulation," meaning that "the sequence and juxtaposition of linguistic terms" suggest that they belong "to the same conceptual sphere." A well-known feature of language use discussed in corpus-based studies-namely, semantic prosodyfurther demonstrates that habitual co-occurrence of lexical items results in evaluative association (Louw, 1993, p. 159). Both these observations together suggest that "chicken serum," while perhaps relatively unproblematic on its own, takes on a quite occult appearance as part of a contextual bestiary. As such, the expanding list continually reinforces its own abject qualities.

Rhetorical listing practices, however, do not constitute lies, and it is important to note that mercury is not included in the list above, despite being the central element of condemnation in the majority of posts in the thread. Presumably, this is because mercury also does not appear in the Centers for Disease Control and Prevention document referred to. Thus, the spread of medical misinformation can in part be attributed to discursive agents, like the poster of the list above, whose output suggest at least a partial commitment to truth. Similar conclusions can be drawn from the pseudoscientific discussion in the $/ \mathrm{pol} /$ thread about which form of mercury is most harmful, and whether the mode of contact matters. Initial agreement that people eat fish, and fish is said to contain higher concentrations of mercury than vaccines, leads to the following hypothe- 
ses: There is a difference between methylmercury (fish) and ethylmercury (vaccines), and injection is intrinsically more dangerous than ingestion. On this issue, the anonymous posters institute a micro-community of amateur researchers, each contributing pieces of the puzzle as to where exactly the dangerous qualities of a particular chemical element reside. However, the discussion, as well as the arguments developed, remain fragmented. Before consensus can be reached on any topic, new links and materials are constantly introduced, as in the following post:

RFK jr/mercury/thimerisol is a big rabbit hole. Also can look int fluoridation levels in brain. MMR/Brian Hooker FOIA. And there was a woman in Utah IIRC, Markwitz or similar. Who found a link between vaccines and autism, caused by contamination from LABORATORY RATS that gave tens of millions of Americans autism via vaccine. The feds locked her up after a Russian scientist wrote a follow up to her paper, and told her they'd ruin her if she didn't tell everyone she made it up (which they did). This was around 2010. Before this she was a leading scientist and researcher of penicillin in the $80 \mathrm{~s} . . . .1$ hope that helps, They're making it hard to find this stuff. (Anonymous, 2019)

In this fragment, listing has a very different effect from that observed in the list of ingredients discussed above. Listing may indicate "an imprecise image of the universe" for speakers who are yet to decide upon the exact relation among the variety of concepts and entities that populate their mental and physical world (Eco, 2009, p. 18). The juxtaposed abbreviations in the quote above signal frustration in terms of the ability to produce a coherent mental picture of the relation between various factors in anti-vaccination discourse. Yet, rather than reflecting upon the disorder within the mind, the poster projects confusion outward, and proposes a conspiracy: "They're making it hard to find this stuff." A malevolent entity is out there, consciously making it difficult for humans to process important information.

The metaphor the poster starts out with presents the image of an inherently confusing, alternative reality: 'a big rabbit hole.' The origins of this idiom, as is well known, lie with Lewis Carroll's Alice In Wonderland (1865). This novel boasts a character named the Mad Hatter. It is widely assumed that this character was inspired by the prevalence of psychotic symptoms among hatters in Victorian Britain, directly related to the introduction of mercury in the process of manufacturing hats (Waldron, 1983, p. 1961). There is evidence to suggest, however, that the Mad Hatter character was simply based on a hat-donning eccentric known to Carroll (Waldron, 1983, p. 1961). Such curious co-occurrences illustrate that there will always be further investigative alleys for the chemically suspicious to explore. Consciously or not, language rephrases language, and correspon- dences across utterances, be they written or oral, reveal that "any text is constructed as a mosaic of quotations; any text is the absorption and transformation of another" (Kristeva, 1986, p. 37). In the time of search engines and hyperlinked media ecosystems, intertextuality is not a hidden phenomenon to be foregrounded, but the default mode of information processing. The Mad Hatter example reveals how the Internet facilitates a descent into rabbit hole upon rabbit hole for those who are so inclined. One is also confronted, in this regard, with the close affiliation between the conspiracy theorist and the researcher: Both establish links and patterns while seeking to unearth the truth, and both may fall victim to apophenia - the perception of patterns where perhaps none can be said to exist (Dixon, 2012, p. 195).

In humans, "pattern recognition can be seen as matching the incoming visual stimuli to existing mental models" (Dixon, 2012, p. 194). Thus, recognizing a pattern reinforces the expectation of the pattern, and the ability to perceive connections and correspondences is a process that fundamentally relies on repetition. In order to see whether there are repeated visual elements on the surface of the Internet that are strongly associated with the practice of listing vaccine ingredients, I queried Google Images for the terms 'vaccinations ingredients.' One repeated image stood out, as the first page of results contained a number of very similar iterations (Figure 2): The first variant, directing to Pinterest, consists of a syringe with its needle inside a small container bearing the inscription 'poison,' as well as the image of a skull. Above this shape one reads "Do you know what's in a vaccine?" (Gorski, n.d.) Around the syringe are listed ingredients and their supposed effects: "Mercury [thimerosal]: One of the most poisonous substances known. Has an affinity for the brain, gut, liver, bone marrow and kidneys. Minute amounts can cause nerve damage. Symptoms of mercury toxicity are similar to those of AUTISM" (Gorksi, n.d.).

A nearly identical image, sourced from a Facebook group, follows closely in Google Images (the third variant in Figure 2), with the heading reading: "Do you know if these are contained in vaccines and why?" (Refutations to Anti-Vaccine Memes, 2013). Instead of being dipped in poison, however, the syringe is dipped in a container labelled 'refutations to anti-vaccine memes.' This inscription is clearly and amateurishly pasted over the previous label, making it obvious that the figure of the syringe was copied to explicitly disrupt an earlier antivaccination variant. A similar list of ingredients appears around the syringe, with examples such as the following: "Mercury [thimerosal]: These are not the same thing. There is no pure mercury in vaccines. Thimerosal is used in some multi-dose influenza vials as a preservative, but no other vaccines contain it" (Refutations to Anti-Vaccine Memes, 2013).

A final almost identical image (the middle variant in Figure 2), taken from a website dedicated to combatting disinformation on vaccines, presents the syringe with its 


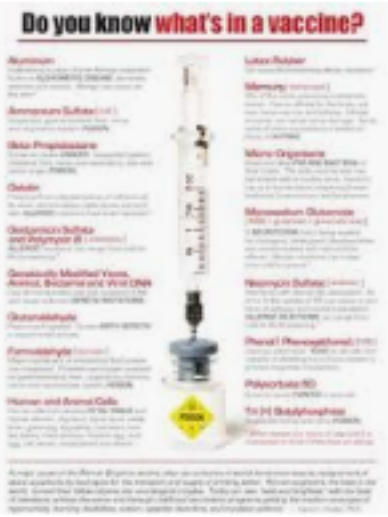

Paige Gorski (sweetpai. pinterest.com

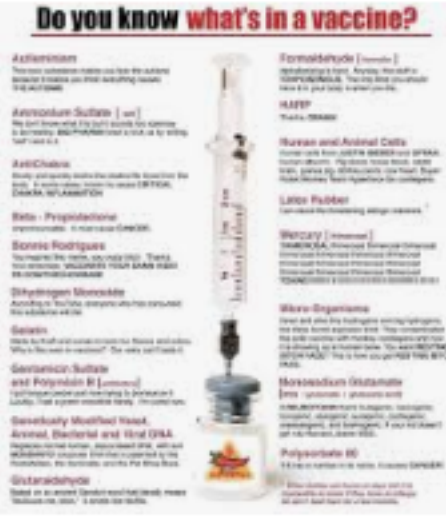

Antivax Myth: "Vaccines co... vaccine.fyi

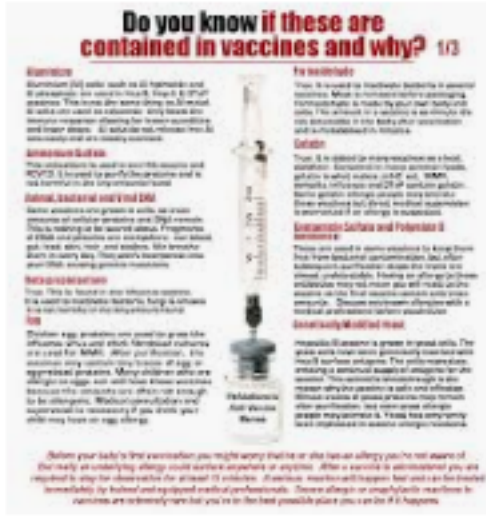

Have you ever read one of tho. fr-fr.facebook.com

Figure 2. Template of the syringe used for conflicting purposes. Source: Google Images (2019).

needle in a container labelled "extra spicy" beneath a red pepper (Babe, 2019). Among the ingredients listed are 'Autisminiam,' and also the following:

\section{Mercury [thimerosal] THIMEROSAL thimerosal thimerosal thimerosal thimerosal thimerosal thimerosal thimerosal thimerosal thimerosal thimerosal thimerosal thimerosal thimerosal thimerosal thimerosal TOXINS!!!!!!!1111!!1!!!1!!!1! 1!!!!!!!!!!11!!11. (Babe, 2019)}

The purpose of this iteration of the meme is to ridicule people who are suspicious about vaccines. Textual incoherence and frustration, elements also observed in conspiratorial posts on the 4 chan thread, provide ample material for ironic treatment. This version of the meme also lists several animal parts and explicitly belittles people who react to science emotionally. Google presented the three variants near each other, and only upon clicking the image does the text become readable, presented in its proper environment. As mentioned, the first image discussed appeared on a Pinterest page, the third one on a Facebook page, and the middle one a website dedicated to expelling anti-vaccination myths. Instantiations of the template mocking anti-vaccination discourse are numerically dominant on Google Images. However, the template itself may suit the spread of vaccine hesitancy. Mockery does not change the fact that lists of unfamiliar ingredients, whether explained or not, may inspire fear or suspicion. Huntington (2016) has made the case for memes as rhetorically reliant upon synecdoche: a part comes to represent the whole. The shape of the syringe as a representation of vaccination practice in general, even if it used to debunk health misinformation, is likely to reinforce anti-vaccine sentiment, regardless of where it occurs, regardless of which arguments accompany it, and regardless of the intentions of the person sharing the image. Gandhi's memetic insertion into the vaccination debate, on the other hand, is unlikely to spread mis- information because of his association with the absurd. The pattern of irony overrides his potential argumentative force. The meme, in short, is self-effacing.

\section{Conclusion}

Memes contribute to the spread of health misinformation, but assessing their ultimate impact is not a straightforward procedure. 4chan, and more specifically /pol/, served as a starting point for the discussion above and led to the identification of two templates with a distinctive contour that circulate across platforms as part of the vaccine debate: the quoted head and the syringe. I exemplified, with reference to the syringe and the list of ingredients, how templates used by anti-vaccination campaigners are copied by their adversaries. While the template was thus transformed into a meme signalling irony rather than (mis)information, I suggested that the strategy is not necessarily effective due to general aversion to the needle's contour. A meme's reception, regardless of its textual content, may be heavily determined by the affective response to its visual outline. I also aimed to show that, as memes are replicated, ironic repurposing tends to develop into purely self-reflective iterations of the template, making any content associated with a particular image macro easily dismissible. In this regard, I discussed the expectation of unbelief that the profile of Gandhi inspires, and the way this neutralizes his authority and potential impact in the vaccine debate. In the introduction I argued that the success of a meme depends upon its capacity to have its meaning radically transformed. As the cases discussed illustrate, transformative potential supports a meme's proliferation but also contributes to the demise of its constative value. Popular memes are often short-lived, as they are quickly exhausted by endless iterations. From this perspective, one could argue that memetic content spreading misinformation should be subjected to an accelerative treatment: If a considerable amount of memes citing anti- 
vaccination activists is circulated in a limited time span, the textual and visual rhetoric associated with these replicators will become ineffective.

This stance would find tentative support in the fact that on 4chan the term 'meme' is used not just with reference to semiotic templates, but also to label broad cultural phenomena, in which case the term usually has the connotation of 'worthless,' 'untrue,' or 'outdated.' The 4 plebs /pol/ archive is rich in discussions on 'meme ideologies.' Proposing for instance, that communism is a meme ideology is equivalent to suggesting that it is a mere discursive position not corresponding to any potential state of affairs. The verb 'to meme' occurs as well, as in the following post on a thread that discusses a reported case of hantavirus in the context of the global COVID-19 outbreak: "Are we gonna meme hanta chan into a global pandemic too?" (Anonymous, 2020b).

In this context, 'to meme' means to inflate something's impact beyond correct proportion, or to escalate a situation through misinformation. Here, agency is claimed on the part of the poster and his peers, but often 4chan presents cultural memes as being produced by external agents, as an example from the thread discussed above illustrates: "What about vaccines without aluminium, carcinogens, human and animal tissues? Can I get that? No I didn't think so. Vaccines are a meme" (Anonymous, 2019).

In the above statements, memes are framed as cultural phenomena that are fundamentally without substance, despite circulating widely. In other words, ongoing semantic changes suggest that once a set of ideas becomes the target of a large number of cultural replicators, independent of whether they are or are not supportive of the ideas in question, the suspicion of an absence of substance is raised. Or, in short: The more memes a topic inspires, the more the topic will be considered 'a meme.' On first sight, this would strengthen the case for accelerating and thereby exhausting the rapid spread of potentially dangerous memes. However, the post labelling vaccines as 'a meme' bears witness not just to a lack of belief in their value, but also to conspiratorial agency: If something circulates widely despite lacking necessity or truth, someone must be behind the successful process of dissemination. In the final analysis, then, spreading memes to subvert them may result in increased pathways for conspiratorial thinking, and should be avoided after all. As memes lose their connection to any identifiable origin, an origin is invented. The levels of suspicion one can create in this manner are endless, as the following response from the thread discussed above illustrates:

They want to feel like they are in on a gigantic secret, to expose the 'man,' the sneering scientist using dem big words with their good ol' honest down to earth wisdom...it is a wonderful chaff to misdirect discourse from actual topics into an endless vortex of shitposting and dumb memes. (Anonymous, 2019)
The post aims to provide insight into the motivations of anti-vaccine proponents. It argues that conspiratorial thought opposes common sense to expertise, and that felicitous self-aggrandizement depends upon an imaginary conflict with evil forces. The poster's final reflection, however, imitates the procedure he derides: anti-vaccination discourse is presented as a bait conspiracy drawing away attention from the actual evil machinations of powerful forces behind the memetic scene. This attitude is a reminder that conflicts of information in anti-vaccination discourse are but a single instance of a much broader tendency to suspect a malevolent agent behind a variety of social practices and conventions. As with image macros, the content is variable but the template is set.

\section{Acknowledgments}

The author acknowledges the support of the Genealogies of Knowledge Research Network, and would like to thank Mona Baker and Henry Jones for commenting on earlier versions of this article. Further thanks go out to the anonymous reviewers for their balanced and insightful comments.

\section{Conflict of Interests}

The author declares no conflict of interests.

\section{References}

4plebs. (2020). Statistics. 4plebs. Retrieved from https:// archive.4plebs.org/pol/statistics

American Psychiatric Association. (2013). Diagnostic and statistical manual of mental disorders: DSM-5. Arlington, VA: American Psychiatric Association.

Anonymous. (2017). Welcome to/pol/: Politically Incorrect. 4chan. Retrieved from http://boards.4chan. org/pol/

Anonymous. (2019). Vaccine debate. 4plebs. Retrieved from https://archive.4plebs.org/pol/thread/ 213971093/\#q213971093

Anonymous. (2020a). Claiming the rainbow, a symbol of segregation. 4plebs. Retrieved from https://archive. 4plebs.org/pol/thread/246905619/\#246905619

Anonymous. (2020b). /hvg/: Hanta Virus General \#3: End of the world edition. 4plebs. Retrieved from https://archive.4plebs.org/pol/thread/249969204/ \#249970121

Atkins, J., \& Finlayson, A. (2016). 'As Shakespeare so memorably said...': Quotation, rhetoric, and the performance of politics. Political Studies, 64(1), 164-181.

Aupers, S. (2012). 'Trust no one': Modernization, paranoia and conspiracy culture. European Journal of Communication, 27(1), 22-34.

AZ Quotes. (2020). Popular authors. AZ Quotes. Retrieved from https://www.azquotes.com

Babe, Chow. (2019). Do you know what's in a vaccine? 
Vaccine.fyi. Retrieved from http://vaccine.fyi/wpcontent/uploads/2016/11/do-you-know-whats-invaccine-ingredients-chow-babe.jpg

Barkun, M. (2013). Culture of conspiracy: Apocalyptic visions in contemporary America. Berkeley, CA: University of California Press.

Bernstein, M. S., Monroy-Hernández, A., Harry, D., André, P., Panovich, K., \& Vargas, G. (2011). 4chan and /b/: An analysis of anonymity and ephemerality in a large online community. In M. P. Simmons, L. A. Adamic, \& E. Adar (Eds.), Proceedings of the fifth international AAAl conference on weblogs and social media (pp. 50-57). Menlo Park CA: The AAAI Press.

BrainyQuote. (2020). Authors to explore. BrainyQuote. Retrieved from https://www.brainyquote.com

Brimnes, N. (2017). Fallacy, sacrilege, betrayal and conspiracy: The cultural construction of opposition to immunisation in India. In C. Holberg, S. Blume, \& P. Greenough (Eds.), The politics of vaccination: $A$ global history (pp. 53-76). Manchester: Manchester University Press.

Carroll, L. (1865). Alice's adventures in Wonderland. London: Macmillan.

Chadwick, A. (2006). Internet politics: States, citizens, and new communication technologies. Oxford and New York, NY: Oxford University Press.

Corn, D. (2017). Here's the Alex Jones story Megyn Kelly and other reporters should probe. Mother Jones. Retrieved from https://www.motherjones.com/ politics/2017/06/alex-jones-megyn-kelly-donaldtrump

Curran, J. (2012). Reinterpreting the Internet. In J. Curran, N. Fenton, \& D. Freedman (Eds.), Misunderstanding the Internet (pp. 3-33). London and New York, NY: Routledge.

Dawkins, R. (2003). The selfish gene (30th anniversary ed.). Oxford: Oxford University Press.

Dennett, D. C. (2017). From bacteria to bach and back: The evolution of minds. New York, NY: W. W. Norton.

Dixon, D. (2012). Analysis tool or research methodology: Is there an epistemology for patterns? In D. M. Berry (Ed.), Understanding digital humanities (pp. 191-209). Basingstoke: Palgrave Macmillan.

Douglas, K. M., Sutton, R. M., \& Cichocka, A. (2017). The psychology of conspiracy theories. Current Directions in Psychological Science, 26(6), 538-542.

Eco, U. (2009). The infinity of lists: From Homer to Joyce (A. McEwen, Trans.). London: Maclehose Press.

Ellis, E. G. (2019). Pepe the Frog means something different in Hong Kong: Right? Wired. Retrieved from https://www.wired.com/story/pepe-the-frogmeme-hong-kong

Fichera, A. (2020). New coronavirus wasn't 'predicted' in simulation. Fact Check. Retrieved from https:// www.factcheck.org/2020/01/new-coronaviruswasnt-predicted-in-simulation

Gandhi, M. (1921). A guide to health (A. R. Iyer, Trans.). Triplicane: S. Ganesan.
Goodreads. (2020). Popular quotes. Goodreads. Retrieved from https://www.goodreads.com/quotes

Google Images. (2019). Google Images search. Google. Retrieved from https://www.google.com/imghp

Gorski, P. (n.d.). Arguments against vaccinations. Pinterest. Retrieved from https://www.pinterest.ie/ sweetpaigey1234/arguments-against-vaccinations

Harambam, J., \& Aupers, S. (2015). Contesting epistemic authority: Conspiracy theories on the boundaries of science. Public Understanding of Science, 24(4), 466-480.

Hern, A. (2018, August 6). Facebook, Apply, YouTube and Spotify ban Infowars' Alex Jones. The Guardian. Retrieved from https://www.theguardian.com/ technology/2018/aug/06/apple-removes-podcastsinfowars-alex-jones

Hine, G. E., Onaolapo, J., De Cristofaro, E., Kourtellis, N., Leontiadis, I., Samaras, R., . . Blackburn, J. (2017). Kek, cucks, and god emperor Trump: A measurement study of 4chan's politically incorrect forum and its effects on the Web. In O. Varol, E. Ferrara, C. A. Davis, F. Menczer, \& A. Flammini (Eds.), Proceedings of the eleventh international $A A A l$ conference on web and social media (pp. 92-101). Palo Alto, CA: The AAAl Press.

Holberg, C., Blume, S., \& Greenough, P. (Eds.). (2017). The politics of vaccination: A global history. Manchester: Manchester University Press.

Hunt, E. (2017, May 8). Pepe the Frog creator kills off Internet meme co-opted by white supremacists. The Guardian. Retrieved from https://www.theguardian. $\mathrm{com} /$ world/2017/may/08/pepe-the-frog-creatorkills-off-Internet-meme-co-opted-by-whitesupremacists

Huntington, H. E. (2016). Pepper spray cop and the American dream: Using synecdoche and metaphor to unlock Internet memes' visual political rhetoric. Communication Studies, 67(1), 77-93.

Kata, A. (2011). Anti-vaccine activists, web 2.0, and the postmodern paradigm: Tactics and tropes used online by the anti-vaccination movement. Vaccine, 30 , 3778-3789.

Keeley, B. L. (1999). Of conspiracy theories. The Journal of Philosophy, 96(3), 109-126.

Kennedy, J. (2019). Populist politics and vaccine hesitancy in Western Europe: An analysis of nationallevel data. The European Journal of Public Health, 29(3), 512-516.

Know Your Meme. (2016). It's just a prank. Know Your Meme. Retrieved from https://knowyourmeme. com/photos/1123057-its-just-a-prank

Kristeva, J. (1986). Word, dialogue and novel. In T. Moi (Ed.), The Kristeva reader (pp. 34-61). Oxford and Cambridge: Blackwell.

Louw, B. (1993). Irony in the text or insincerity in the writer: The diagnostic potential of semantic prosody. In M. Baker, G. Francis, \& E. Tognini-Bonelli (Eds.), Text and technology: In honour of John Sinclair (pp. 
157-176). Amsterdam and Philadelphia, PA: John Benjamins Publishing Company.

Me.me. (n.d.). Memetic Mantra. Meme. Retrieved from https://me.me/i/you-must-be-the-meme-you-wishto-see-in-500969600d1c41588b1786ab0a194160

Motta, M. (2018). The dynamics and political implications of anti-intellectualism in the United States. American Politics Research, 46(3), 465-498.

Mourad, S. (2020, January 21). Anti-vaxxer's very sneaky move. Daily Mail. Retrieved from https://www. dailymail.co.uk/news/article-7909635/Australiananti-vaxxer-political-party-tries-change-InformedMedical-Options-Party.html

Nissenbaum, A., \& Shifman, L. (2017). Internet memes as contested cultural capital: The case of 4chan's /b/ board. New Media \& Society, 19(4), 483-501.

Pelletier-Gagnon, J., \& Diniz, A. P. T. (2018). Colonizing Pepe: Internet memes as cyberplaces. Space and Culture. https://doi.org/10.1177/1206331218776188

Phillips, W. (2012). The house that fox built: Anonymous, spectacle, and cycles of amplification. Television \& New Media, 14(6), 494-509.

Refutations to Anti-Vaccine Memes. (2013). Vaccine ingredients. Facebook. Retrieved from https://www. facebook.com/RtAVM/posts/496929833710364

Urban, G. (2001). Metaculture: How culture moves through the world. Minneapolis, MN: University of
Minnesota Press.

u/dchubbs. (2013). Bitches ain't shit but hoes and tricks - Ghandi [1680x1050]. Reddit. Retrieved from https://www.reddit.com/r/ShittyQuotesPorn/ comments/16a9se/bitches_aint_shit_but_hoes_ and_tricks_ghandi/

Wakefield, A. J., Murch, S. H., Anthony, A., Linnell, J., Casson, D. M., Malik, M., . . . \& Valentine, A. (1998). Retracted: Ileal-lymphoid-nodular hyperplasia, nonspecific colitis, and pervasive developmental disorder in children. The Lancet, 351, 637-41.

Waldron, H. A. (1983). Did the mad hatter have mercury poisoning? British Medical Journal, 287. https:// doi.org/10.1136/bmj.287.6409.1961

World Health Organization. (2019). Ten threats to global health in 2019. World Health Organization. Retrieved from https://www.who.int/emergencies/ ten-threats-to-global-health-in-2019

Zannettou, S., Caulfield, T., De Cristofaro, E., Kourtellis, N., Leontiadis, I., Sirivianos, M., . . Blackburn, J. (2017). The web centipede: Understanding how web communities influence each other through the lens of mainstream and alternative news sources. In S. Ulig \& O. Maennel (Eds.), Proceedings of the IMC '17 London (pp. 1-14). New York, NY: Association for Computer Machinery.

\section{About the Author}

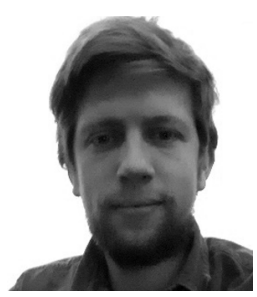

Jan Buts is a Postdoctoral Researcher attached to the QuantiQual Project at Trinity College Dublin, and a Co-Coordinator of the Genealogies of Knowledge Research Network. He works at the intersection of translation theory, conceptual history, corpus linguistics, and online media. 